\title{
Theoretical Virtues in Scientific Practice: An Empirical Study
}

\author{
Moti Mizrahi
}

\begin{abstract}
It is a common view among philosophers of science that theoretical virtues (also known as epistemic or cognitive values), such as simplicity and consistency, play an important role in scientific practice. In this paper, I set out to study the role that theoretical virtues play in scientific practice empirically. I apply the methods of data science, such as text mining and corpus analysis, to study large corpora of scientific texts in order to uncover patterns of usage. These patterns of usage, in turn, might shed some light on the role that theoretical virtues play in scientific practice. Overall, the results of this empirical study suggest that scientists invoke theoretical virtues explicitly, albeit rather infrequently, when they talk about models (less than $30 \%$ ), theories (less than 20\%), and hypotheses (less than 15\%) in their published works. To the extent that they are mentioned in scientific publications, the results of this study suggest that accuracy, consistency, and simplicity are the theoretical virtues that scientists invoke more frequently than the other theoretical virtues tested in this study. Interestingly, however, depending on whether they talk about hypotheses, theories, or models, scientists may invoke one of those theoretical virtues more than the others.
\end{abstract}

\section{Introduction \\ 2. Methods \\ 3. Results \\ 4. Discussion \\ Appendix}

\section{Introduction}

It is a common view among philosophers of science that theoretical virtues (also known as epistemic or cognitive values), such as simplicity and consistency, play an important role in scientific practice. For instance, according to Elgin ([2017], p. 128), 'science incorporates values that are simultaneously moral and epistemic'. As far as theoretical virtues in science are concerned, Kuhn ([2000], p. 251) provides 'the standard list of criteria for evaluating scientific belief', which includes the following properties: 'Accuracy, precision, scope, simplicity, fruitfulness, [and] consistency'. Similarly, Longino ([1995], p. 383), who uses the phrase 'theoretical virtues' as well as 'cognitive virtues', includes 'accuracy, simplicity, internal and external consistency, breadth of scope, and fruitfulness' in her list. Together with explanatory power, these are what Longino ([1995], p. 384) calls 'constitutive values', which she distinguishes from what she calls 'contextual values', which are 'social or practical interests'. According to Laudan ([1984], p. xii), 'an attribute will count as a cognitive value or aim if that attribute represents a property of theories which we deem to be constitutive of "good science". For example, as Baker ([2016]) observes, 'Most philosophers believe that, other things being equal, simpler theories are better'. Accordingly, of two scientific theories, $T_{1}$ and $T_{2}, T_{1}$ would be 
considered a better theory than $T_{2}$ if $T_{1}$ is simpler than $T_{2}$, other things being equal. The same goes for the other properties on Kuhn's list of theoretical virtues. ${ }^{1}$

It is worth noting that even scientific antirealists do not deny that theoretical virtues play an important role in scientific practice. What they typically deny, however, is that these theoretical virtues are truth-conducive. For example, van Fraassen ([1980], p. 4) argues that theoretical virtues, such as simplicity, are merely pragmatic virtues, which 'do not give us any reason over and above the evidence of the empirical data, for thinking that a theory is true'. But he does not deny that such pragmatic virtues play an important role in scientific practice. As van Fraassen ([1980], p. 87) puts it, 'When a theory is advocated, it is praised for many features other than empirical adequacy and strength: it is said to be mathematically elegant, simple, of great scope, complete in certain respects: also of wonderful use in unifying our account of hitherto disparate phenomena, and most of all, explanatory'.

One might wonder, however, if philosophers of science are right to think that theoretical virtues play an important role in scientific practice. One can surely find selected examples of scientists invoking one of a theoretical virtue. For example (emphasis added):

We have now examined the principal phenomena which are reducible to the simple theory of the action of the superficial particles of a fluid (Young [1805], p. 81).

But then one might worry whether such examples are representative of science as a whole. ${ }^{2}$ In this paper, then, I propose to take an empirical approach to the question about 'the characteristics of a theory which scientists value and which guide them in their choice to adopt one theory or another' (Schindler [2018a], p. 5; emphasis added). Do theoretical virtues really guide scientists in theory choice? Do scientists make explicit appeals to theoretical virtues in scientific practice? If so, which theoretical virtues? How frequently do scientists appeal to those theoretical virtues in scientific practice? Do they invoke some theoretical virtues more than others? If so, which ones? I think that the tools of data science can help us shed some light on these questions. By using the text mining, corpus analysis, and data visualization techniques of data science, we can study large corpora of scientific texts in order to uncover patterns of usage. These patterns of usage, in turn, might shed some light on the role that theoretical virtues play in scientific practice. $^{3}$

In Section 2, I will describe the methods I have used in this empirical study of theoretical virtues in scientific practice. In Section 3, I will report the results of this study. In Section 4, I will discuss the implications of the results of this study as far as the philosophical debate

\footnotetext{
${ }^{1}$ For a more comprehensive list of theoretical virtues, which includes accuracy, causal adequacy, explanatory depth, consistency, coherence, beauty, simplicity, unification, durability, fruitfulness, and applicability, see Keas ([2018]).

${ }^{2}$ On the methodological problems associated with using case studies from the history of science as evidence in philosophy of science, see Sauer and Scholl ([2016], pp. 1-10), Bolinska and Martin ([2019]), and Mizrahi ([2020]). ${ }^{3}$ On the application of the methods of data science, such as data mining and corpus analysis, to philosophy of science, see Mizrahi ([2013]) and Mizrahi ([2016]). For a recent example of an application of survey and other methodologies from the social sciences to philosophy of science, see Beebe and Dellsén ([2020]). On experimental philosophy of science, see Machery ([2016]).
} 
concerning the role of theoretical virtues in scientific practice is concerned. ${ }^{4}$ Overall, the results of this study suggest that scientists invoke theoretical virtues explicitly, albeit rather infrequently, when they talk about models (less than 30\%), theories (less than 20\%), and hypotheses (less than $15 \%$ ) in their published works. To the extent that they are mentioned in scientific publications, the results of this study suggest that accuracy, consistency, and simplicity are the theoretical virtues that scientists invoke more frequently than the other theoretical virtues tested in this study. Interestingly, however, depending on whether they talk about hypotheses, theories, or models, scientists may invoke one of those theoretical virtues more than the others.

\section{Methods}

As discussed in Section 1, the research questions that guide this empirical study of theoretical virtues in scientific practice are as follows: Do scientists make explicit appeals to theoretical virtues in scientific practice? If so, which theoretical virtues? How frequently do scientists appeal to those theoretical virtues? Do they invoke some theoretical virtues more than others? If so, which ones?

By adopting the methods of data science, I propose, we can find tentative answers to these questions empirically. The methods of data and text mining allow us to examine large corpora of scientific texts (that is, articles and book chapters published in scientific journals and books) in order to find out whether theoretical virtues really do guide scientists in theory choice. Such data can be mined from JSTOR Data for Research (www.jstor.org/dfr/). Researchers can use JSTOR Data for Research to create datasets, including metadata, n-grams, and word counts, for most of the articles and book chapters contained in the JSTOR database. JSTOR Data for Research is a particularly useful resource for the purposes of this study because it provides an interface for creating datasets based on unique search queries and the associated metadata for those search queries. By using this interface for constructing datasets, then, we can find out whether terms that indicate theoretical virtues appear in scientific publications and with what frequency relative to the total number of publications in a corpus.

The methods of data science allow us to overcome the limitations of relying on selected case studies from the history of science. For those case studies may or may not be representative of science as a whole. As Pitt ([2001], p. 373) puts it, 'if one starts with a case study, it is not clear where to go from there--for it is unreasonable to generalize from one case or even two or three'. Of course, empirical methodologies have limitations of their own. As far as the methods of data science and corpus linguistics are concerned, there are two major limitations. First, we can only study and analyse what is explicitly mentioned in the corpus. For the purpose of this study, then, the corpus of scientific texts must contain explicit mentions of theoretical virtues, for example, instances of 'accurate', 'simple', and the like, for us to be able to analyse means, proportions, and patterns of usage. It is reasonable to assume that there would be such explicit mentions of theoretical virtues in scientific texts if theoretical virtues really do guide scientists in

\footnotetext{
${ }^{4}$ In addition to the question about whether, and to what extent, theoretical virtues play a role in scientific practice, philosophers of science also deal with questions concerning the nature of the theoretical virtues themselves. See, for example, Ivani ([2019]) on how to explicate fruitfulness and Schindler ([2018b]) on what it means for a hypothesis to be ad hoc. Cf. Nolan ([1999]) for a reductive account of fruitfulness in terms of other theoretical virtues, such as predictive power and accuracy.
} 
theory choice. Indeed, it would be quite surprising if theoretical virtues played an important role in scientific practice but were not explicitly mentioned in scientific publications.

Second, as with any empirical methodology, there may be some false positives and/or false negatives. When it comes to the methods of data science and corpus linguistics, false negatives could occur when we search for a specific term $t$ in a corpus, but do not find it, even though the corpus contains a synonym of $t$. For example, although unlikely, it is possible that our corpus of scientific texts contains no instances of 'simple', and so a search for 'simple theory' would return zero results, because scientists use 'uncomplicated' instead of 'simple' in all the publications that make up our corpus. On the other hand, false positives could occur when we find instances of a term $t$ in our corpus, but those instances contain irrelevant uses of $t$. For the purpose of this study, then, the corpus of scientific texts must contain not only explicit mentions of theoretical virtues, for example, instances of 'accurate', 'simple', and the like, but also explicit mentions of theoretical virtues in the context of talk about theories. For example, instances of 'simple' that are not about theories (as in 'simple theory') would be considered false positives for the purposes of this study.

Now, there are two things we can do to overcome the limitations of our empirical, datadriven approach. First, we can refine our search terms. For the purposes of this study, I have followed Schindler's ([2018a]) comprehensive study of theoretical virtues in science. Following Schindler ([2018a], p. 6), I have restricted this study 'to Kuhn's five standard virtues, testability, and ad hocness'. As Schindler ([2018a], p. 5) points out, testability 'is widely regarded as a minimal condition for a good scientific theory'. To minimize the number of false negatives as much as possible, we can search for both adjectives and nouns that express theoretical virtues in text. That is, we can search for instances of 'simple', as in 'simple theory', as well as 'simplicity', as in 'the theoretical virtue of simplicity'. Moreover, we can expand our search queries to include other terms that indicate simplicity as a theoretical virtue in scientific publications. For example, in addition to 'simplicity', philosophers of science often use the term 'parsimony' to talk about the same theoretical virtue. As Baker ([2016]) puts it, 'Syntactic simplicity, or elegance, measures the number and conciseness of the theory's basic principles. Ontological simplicity, or parsimony, measures the number of kinds of entities postulated by the theory'. Accordingly, if we include the terms 'parsimony' and 'parsimonious' in our search queries for simplicity, we can be quite confident that we will not miss instances of simplicity in scientific publications that use the term 'parsimony' rather than 'simplicity'. This search methodology yields the search terms listed in Table 1. It is designed to minimize the number of false negatives, that is, appeals to a theoretical virtue in scientific publications that make use of a term different from the standard term for that theoretical virtue, such as 'parsimony' rather than 'simplicity', 'fit/match with data' rather than 'accuracy', 'fecundity' rather than 'fruitfulness', etc. 
Table 1. Search terms for the theoretical virtues

\begin{tabular}{|l|l|}
\hline $\begin{array}{l}\text { Theoretical } \\
\text { Virtue }\end{array}$ & Search Terms \\
\hline Accuracy & accuracy, accurate, accurately, fit, fitting, match, matching \\
\hline Ad hocness & ad hoc, ad hocness \\
\hline $\begin{array}{l}\text { Breadth of } \\
\text { scope }\end{array}$ & $\begin{array}{l}\text { breadth scope, broad scope, comprehensive, comprehensively, } \\
\text { comprehensiveness }\end{array}$ \\
\hline Consistency & coherence, coherent, coherently, consistency, consistent, consistently \\
\hline Fruitfulness & $\begin{array}{l}\text { fecund, fecundity, fertile, fertility, fruitful, fruitfully, fruitfulness, predictive, } \\
\text { predictively }\end{array}$ \\
\hline Simplicity & $\begin{array}{l}\text { elegance, elegant, elegantly, parsimonious, parsimoniously, parsimony, } \\
\text { simple, simplicity, simplified, simpler, simplest, simply }\end{array}$ \\
\hline Testability & testability, testable \\
\hline
\end{tabular}

Second, we can make sure that our search methodology picks out instances of theoretical virtues in the corpus that occur in the context of talk about hypotheses, models, or theories. Since the aim of this paper is to find out whether scientists are guided by theoretical virtues in scientific practice, that is, whether scientists actually value virtuous theories, I have searched for theoretical virtues in the context of talk about hypotheses, models, or theories by pairing the search terms for theoretical virtues listed in Table 1 with the scientific practice terms 'hypothesis', 'model', and 'theory'. In practice, this means that I have searched for theoretical virtue terms within ten words of the words 'hypothesis', 'model', or 'theory', for example, ("accurate hypothesis" 10), ("accurate model" 10$),$ ("accurate theory" 10), ("consistent hypothesis" 10), ("consistent model" 10), ("consistent theory" 10 ), and so on, according to the following formula (for a complete list of theoretical virtue cum scientific practice search queries, see Appendix I):

("theoretical virtue term 1 scientific practice term" 10 ) OR ("theoretical virtue term 2

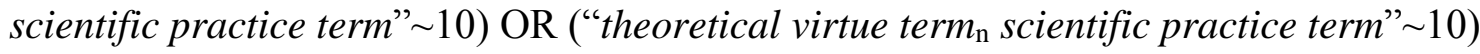

For example: ("accuracy theory" 10) OR ("accurate theory" 10) OR ("accurately theory" 10) OR ("fit theory" 10) OR ("fitting theory" 10) OR ("match theory" 10) OR ("matching theory" 10). This search methodology is designed to minimize the number of false positives, that is, instances of terms for theoretical virtues that are not about scientific hypotheses, models, or theories, by ensuring that instances of terms for theoretical virtues in text are anchored to the 
scientific practice terms 'hypothesis', 'model', or 'theory' (allowing for only ten words between a term for a theoretical virtue, such as 'simple', and a scientific practice term, such as 'theory'). ${ }^{5}$

To contextualize the statistical results that are reported in Section 3, here are a few examples of the search results that this search methodology picked out (emphasis added):

1. 'any fit between theory and data is as likely to be a matter of fortuitous fitting of parameters as it is to be a matter of capturing the essential processes that explain most of the observed variation' (Frank and Vogelstein [2005], p. 1072).

2. 'Hrdy's cooperative breeding hypothesis (2009) elegantly documents a mechanism by which extramaternal support in early child-rearing environments enabled reduced interbirth intervals in females' (Tomasello et al. [2012], p. 689).

3. 'We find the $A D L$ concept useful in constructing a reasonably accurate model of sky brightness at high zenith distances' (Duriscoe [2013], p. 1371).

4. 'This is a testable hypothesis leading to the prediction that phylogenetically related biological entities with different degrees of unification will also differ in the context dependency of their interactions' (Díaz-Muñoz et al. [2016], p. 2675).

5. 'The simplest hypothesis, that the compact sources evolve with constant radio luminosity and constant advance speed into the large ones, fails because of their large relative numbers' (O’Dea [1998], p. 523).

6. 'Analysis of data from the Thames estuary has highlighted the existence of a linear trend between species diversity and salinity range in this system, creating a testable model for use in other estuaries' (Attrill [2002], p. 268).

On the other hand, this search methodology will not count the following example of a false positive of 'simple' as an occurrence of the theoretical virtue of simplicity in the corpus (emphasis added):

To broaden the ecological space over which the ecological context hypothesis was tested, pollination intensity was incorporated as another factor in the experimental design of the present study. In addition to revealing the complexities around a simple yet underexplored plant trait, the results will also contribute to the broader issue of the significance of ecological context as a determinant of the fitness value of plant reproductive features (Herrera [2011], p. 813).

This is a false positive of 'simple' because what is being described as simple here is not a hypothesis, a model, or a theory, but rather a plant trait, and our search methodology will not count this instance of 'simple' as an instance of the theoretical virtue of simplicity in scientific practice because there are more than ten words between 'hypothesis' and 'simple'.

\footnotetext{
${ }^{5}$ It is important to note that, for proximity search to work properly in the JSTOR Data for Research's dataset construction interface, the correct syntax must be used. In the case of proximity searches, such as the ones conducted for this study, the syntax is ("term 1 term." 10 ), for example, ("simple model" 10 ). Without the parentheses and quotation marks, a search query will yield search results that include text with more than ten words between term 1 and term 2 . As mentioned above, we would like to rule out such search results in order to avoid counting false positives. This syntax for proximity search, however, does not allow for wildcard searches using the asterisk symbol (*), for example, ("simpl* model" 10). To overcome this issue, I used the Boolean operator OR to search for variations of the terms for the theoretical virtues (see Appendix I).
} 
This search methodology is designed to test hypotheses about the role of theoretical virtues in scientific practice as follows: if scientists value virtuous hypotheses, models, and/or theories, and these theoretical virtues guide scientists in theory choice, then we would expect to see frequent occurrences of the search terms for theoretical virtues from Table 1 paired with the scientific practice terms (namely, 'hypothesis', 'model', and 'theory'). Accordingly, if we do find frequent occurrences of our search queries in scientific publications, then that would lend some empirical support to the view that theoretical virtues do play an important role in scientific practice. On the other hand, if we do not find frequent occurrences of our search queries in scientific publications, then that would count as some negative evidence against the view that theoretical virtues play an important role in scientific practice.

In that respect, it is also important to note that, just like any other empirical study, the results of this study are not to be interpreted as conclusive evidence for any hypothesis about the role of theoretical virtues in scientific practice. Nor are the methods used in this study the only (or even the best) methods to study the role of theoretical virtues in scientific practice. Rather, they are supposed to add to our understanding of the role that theoretical virtues play in scientific practice. Other studies, which make use of different empirical methods, such as survey procedures, can do the same (see, for example, Schindler and Saint-Germier [2019]).

The JSTOR database allows for searches by subject, such as Biological Sciences, Physics, and Sociology. In order to have a large and diverse sample that could be representative of science, I have conducted my searches on data mined from the Biological Sciences, Botany \& Plant Sciences, Ecology \& Evolutionary Biology, Astronomy, Chemistry, Physics, Anthropology, Psychology, and Sociology subjects in the JSTOR database. That way, my datasets contain representative disciplines from the life sciences (namely, Biological Sciences, Botany \& Plant Sciences, and Ecology \& Evolutionary Biology), representative disciplines from the physical sciences (namely, Astronomy, Chemistry, and Physics), and representative disciplines from the social sciences (namely, Anthropology, Psychology, and Sociology). For each search query, then, I recorded the search results by scientific subject. All the searches for this study were conducted on 3 December 2019.

\section{Results}

Since the purpose of this empirical study is to test hypotheses about the role of theoretical virtues in scientific practice, we need to get a sense of how frequently the scientific practice terms, namely, 'hypothesis', 'model', and 'theory', are used in scientific publications. Those frequencies will serve as our base rates. Accordingly, I have conducted searches for the terms 'hypothesis', 'model', and 'theory' in the Biological Sciences, Botany \& Plant Sciences, Ecology \& Evolutionary Biology, Astronomy, Chemistry, Physics, Anthropology, Psychology, and Sociology subjects in the JSTOR database. The results of these searches are summarized in Table 2. 
Table 2. Numbers and percentages of publications with occurrences of the scientific practice terms 'hypothesis', 'model', or 'theory' by subject (Source: JSTOR Data for Research)

\begin{tabular}{|c|c|c|c|c|c|c|c|}
\hline & $\begin{array}{l}\text { Total } \\
\text { number } \\
\text { of } \\
\text { publicati } \\
\text { ons }\end{array}$ & $\begin{array}{l}\text { Number } \\
\text { of } \\
\text { publicati } \\
\text { ons that } \\
\text { contain } \\
\text { 'hypothe } \\
\text { sis' }\end{array}$ & $\begin{array}{l}\text { Percenta } \\
\text { ge of } \\
\text { 'hypothe } \\
\text { sis' } \\
\text { publicati } \\
\text { ons in } \\
\text { subject } \\
\text { corpus }\end{array}$ & $\begin{array}{l}\text { Number } \\
\text { of } \\
\text { publicati } \\
\text { ons that } \\
\text { contain } \\
\text { 'model' }\end{array}$ & $\begin{array}{l}\text { Percenta } \\
\text { ge of } \\
\text { 'model' } \\
\text { publicati } \\
\text { ons in } \\
\text { subject } \\
\text { corpus }\end{array}$ & $\begin{array}{l}\text { Number } \\
\text { of } \\
\text { publicati } \\
\text { ons that } \\
\text { contain } \\
\text { 'theory' }\end{array}$ & $\begin{array}{l}\text { Percenta } \\
\text { ge of } \\
\text { 'theory' } \\
\text { publicati } \\
\text { ons in } \\
\text { subject } \\
\text { corpus }\end{array}$ \\
\hline $\begin{array}{l}\text { Biological } \\
\text { Sciences }\end{array}$ & 1300469 & 257835 & $20 \%$ & 384983 & $30 \%$ & 228985 & $18 \%$ \\
\hline $\begin{array}{l}\text { Botany \& } \\
\text { Plant } \\
\text { Sciences }\end{array}$ & 449948 & 60160 & $13 \%$ & 83378 & $18 \%$ & 35398 & $8 \%$ \\
\hline $\begin{array}{l}\text { Ecology \& } \\
\text { Evolution } \\
\text { ary } \\
\text { Biology }\end{array}$ & 349447 & 93935 & $27 \%$ & 135316 & $39 \%$ & 90974 & $26 \%$ \\
\hline $\begin{array}{l}\text { Astronom } \\
\mathbf{y}\end{array}$ & 18137 & 1960 & $11 \%$ & 5027 & $28 \%$ & 3642 & $20 \%$ \\
\hline Chemistry & 761 & 101 & $13 \%$ & 202 & $26 \%$ & 237 & $31 \%$ \\
\hline Physics & 5493 & 1022 & $19 \%$ & 2386 & $43 \%$ & 3115 & $57 \%$ \\
\hline $\begin{array}{l}\text { Anthropol } \\
\text { ogy }\end{array}$ & 328552 & 26835 & $8 \%$ & 64948 & $20 \%$ & 82585 & $25 \%$ \\
\hline $\begin{array}{l}\text { Psycholog } \\
\mathbf{y}\end{array}$ & 88207 & 23185 & $26 \%$ & 33820 & $38 \%$ & 43402 & $49 \%$ \\
\hline Sociology & 705573 & 67731 & $10 \%$ & 190483 & $27 \%$ & 251369 & $36 \%$ \\
\hline
\end{tabular}

Now that we have our prior probabilities of scientific publications that contain the scientific practice terms, namely, 'hypothesis', 'model', and 'theory', we can look at how frequently these terms occur in conjunction with (that is, within ten words of) the search terms for theoretical virtues from Table 1. (See Appendix I.) That is, we would like to know how frequently theoretical virtues are invoked in the context of talk about hypotheses, models, and theories. Accordingly, frequencies will be calculated by taking the search results for each theoretical virtue and dividing it by the number of publications that contain hypothesis talk, model talk, and theory talk, respectively. For example, $18 \%$ of Biological Sciences publications 
contain theory talk. Now, of those publications, how many contain occurrences of the terms for the theoretical virtues listed in Table 1? Let us begin with theoretical virtues in the context of theory talk. The results of these searches are depicted in Figure 1.

Figure 1. Proportions of publications that contain occurrences of theoretical virtues in the context of theory talk by subject (Source: JSTOR Data for Research)

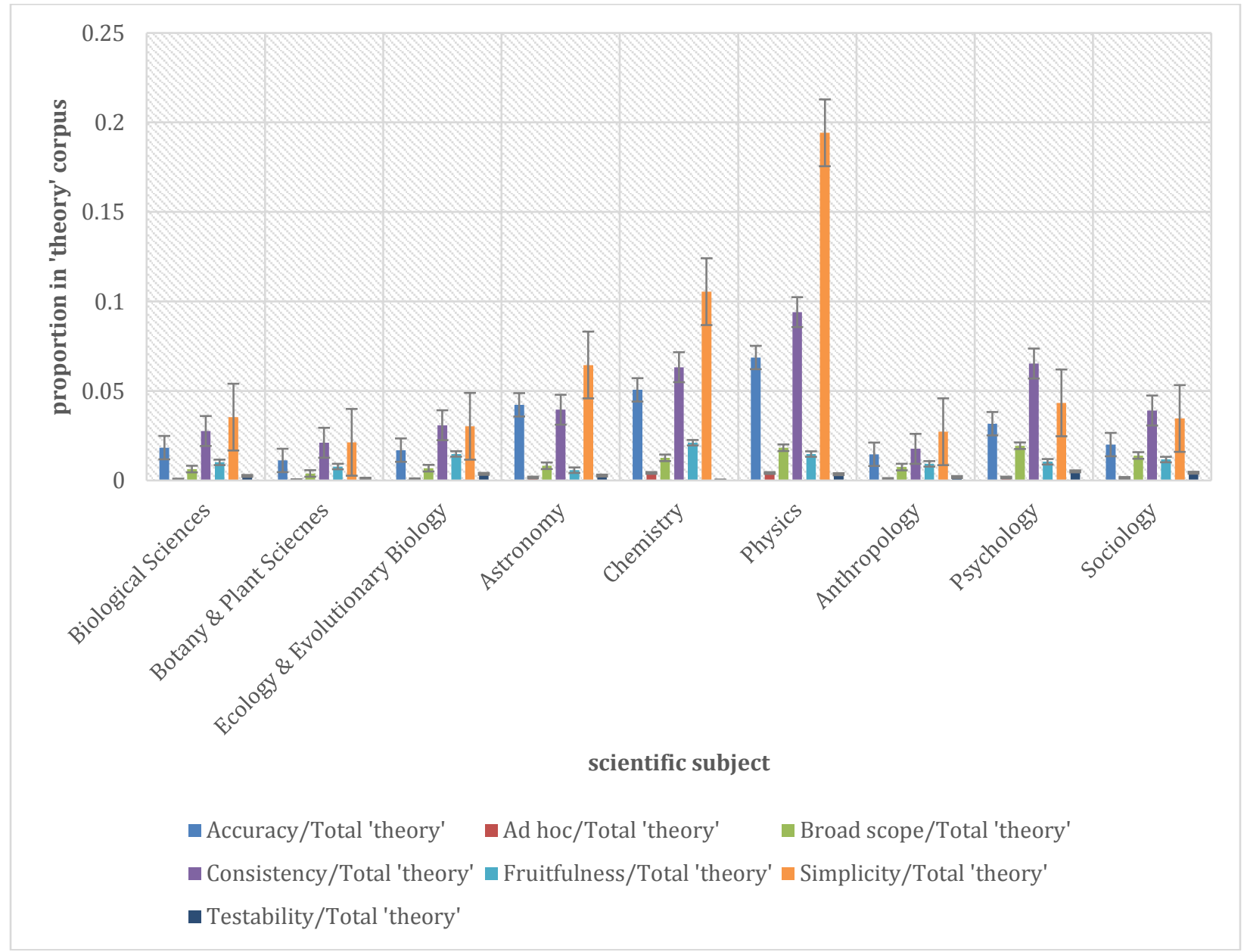

As we can see from Figure 1, overall, theoretical virtues do not occur all that frequently in the context of theory talk. In the physical sciences, the most frequently mentioned theoretical virtue is simplicity: 19\% in Physics, 10\% in Chemistry, and 6\% in Astronomy. The results of ztests for proportions suggest that simplicity is invoked significantly more often than the second most frequently invoked theoretical virtue, namely, consistency, in Physics ( $\mathrm{z}=11.254, p=0.00$, two-sided), and Astronomy ( $\mathrm{z}=4.221, p=0.00$, two-sided), where the second most frequently invoked theoretical virtue is accuracy $(4 \%)$ rather than consistency $(3 \%)$, but not in Chemistry (z $=1.652, p=0.09$, two-sided). These results suggest that simplicity is invoked significantly more often than the other theoretical virtues in Physics and Astronomy publications that contain theory talk, whereas simplicity and consistency are invoked with no significant difference in frequency in Chemistry publications that contain theory talk. 
In the life sciences, simplicity and consistency are mentioned with almost equal frequency: between 2\% and 3\% in the Biological Sciences, Botany \& Plant Sciences, and Ecology \& Evolutionary Biology. To find out if these differences are statistically significant, ztests for proportions were conducted. In the Biological Sciences, the difference between the proportion of publications that mention simplicity (0.03) and the proportion of publications that mention consistency (0.02) is statistically significant ( $\mathrm{z}=15.019, p=0.00$, two-sided). In Botany $\&$ Plant Sciences, the difference between the proportion of publications that mention simplicity (0.02) and the proportion of publications that mention consistency $(0.02)$ is not statistically significant $(\mathrm{z}=0.234, p=0.81$, two-sided). In Ecology \& Evolutionary Biology, the difference between the proportion of publications that mention simplicity $(0.03)$ and the proportion of publications that mention consistency (0.03) is not statistically significant $(\mathrm{z}=0.721, p=0.47$, two-sided), either. These results suggest that simplicity is invoked significantly more often than the other theoretical virtues in Biological Sciences publications that contain theory talk, whereas simplicity and consistency are invoked with no significant difference in frequency in Botany \& Plant Sciences and Ecology \& Evolutionary Biology publications that contain theory talk.

In the social sciences, the most frequently mentioned theoretical virtue is consistency: $6 \%$ in Psychology and 3\% in Sociology. Anthropology is an interesting exception, however, with the proportion of consistency at $1 \%$ and the proportion of simplicity at $2 \%$ in the 'theory' corpus. The result of a z-test for proportions suggests that the difference between the proportion of Anthropology publications that mention simplicity (0.02) and the proportion of Anthropology publications that mention consistency $(0.01)$ in the 'theory' corpus is statistically significant $(\mathrm{z}=$ 13.103, $p=0.00$, two-sided). This result suggests that simplicity is invoked significantly more often than the other theoretical virtues in Anthropology publications that contain theory talk. Likewise, the results of z-tests for proportions suggest that consistency is invoked significantly more often than the second most frequently invoked theoretical virtue, namely, simplicity, in Psychology ( $\mathrm{z}=14.282, p=0.00$, two-sided $)$ and in Sociology $(\mathrm{z}=8.382, p=0.00$, two-sided $)$. These results suggest that consistency is invoked significantly more often than the other theoretical virtues in Psychology and Sociology publications that contain theory talk.

Additional z-tests for proportions were conducted to find that these differences between Anthropology and the other social sciences are statistically significant. Specifically, the difference between the proportion of simplicity in Anthropology publications that contain theory talk (0.02) and the proportion of consistency in Psychology publications that contain theory talk (0.06) is statistically significant $(\mathrm{z}=32.662, p=0.00$, two-sided). Likewise, the difference between the proportion of simplicity in Anthropology publications that contain theory talk (0.02) and the proportion of consistency in Sociology publications that contain theory talk (0.03) is statistically significant $(\mathrm{z}=15.845, p=0.00$, two-sided). These results suggest a significant difference between the social sciences, namely, Anthropology, on the one hand, and Psychology and Sociology, on the other hand. Specifically, while simplicity is invoked more frequently than other theoretical virtues in Anthropology publications that contain theory talk, it is consistency that is invoked more frequently than other theoretical virtues in Psychology and Sociology publications that contain theory talk.

Overall, theoretical virtues are invoked rather infrequently in the context of theory talk across all the scientific subjects tested in this study. To the extent that theoretical virtues are 
invoked in scientific practice, however, there are interesting differences between the scientific subjects. In the physical sciences (Astronomy, Chemistry, and Physics), the results suggest that simplicity plays a more significant role than the other theoretical virtues in Physics and Astronomy publications that contain theory talk, but not in Chemistry publications where there is no significant difference between simplicity and consistency. In the life sciences (Biological Sciences, Botany \& Plant Sciences, and Ecology \& Evolutionary Biology), simplicity plays a more significant role than the other theoretical virtues in Biological Sciences publications that contain theory talk, but not in Botany \& Plant Sciences and Ecology \& Evolutionary Biology publications where there is no significant difference between simplicity and consistency. In the social sciences (Anthropology, Psychology, and Sociology), consistency plays a more significant role than the other theoretical virtues in Psychology and Sociology publications that contain theory talk, but not in Anthropology publications where simplicity plays a more significant role than the other theoretical virtues. In that respect, Anthropology publications look more like Physics and Astronomy publications than publications in the other social sciences.

Somewhat different results were obtained when searching for the theoretical virtues in the context of hypothesis talk. The results of these searches are depicted in Figure 2. As we can see from Figure 2, like in the case of theory talk, theoretical virtues do not occur all that frequently in the context of hypothesis talk as well. Nevertheless, there are interesting differences between the 'hypothesis' corpus and the 'theory' corpus.

Figure 2. Proportions of publications that contain occurrences of theoretical virtues in the context of hypothesis talk by subject (Source: JSTOR Data for Research) 

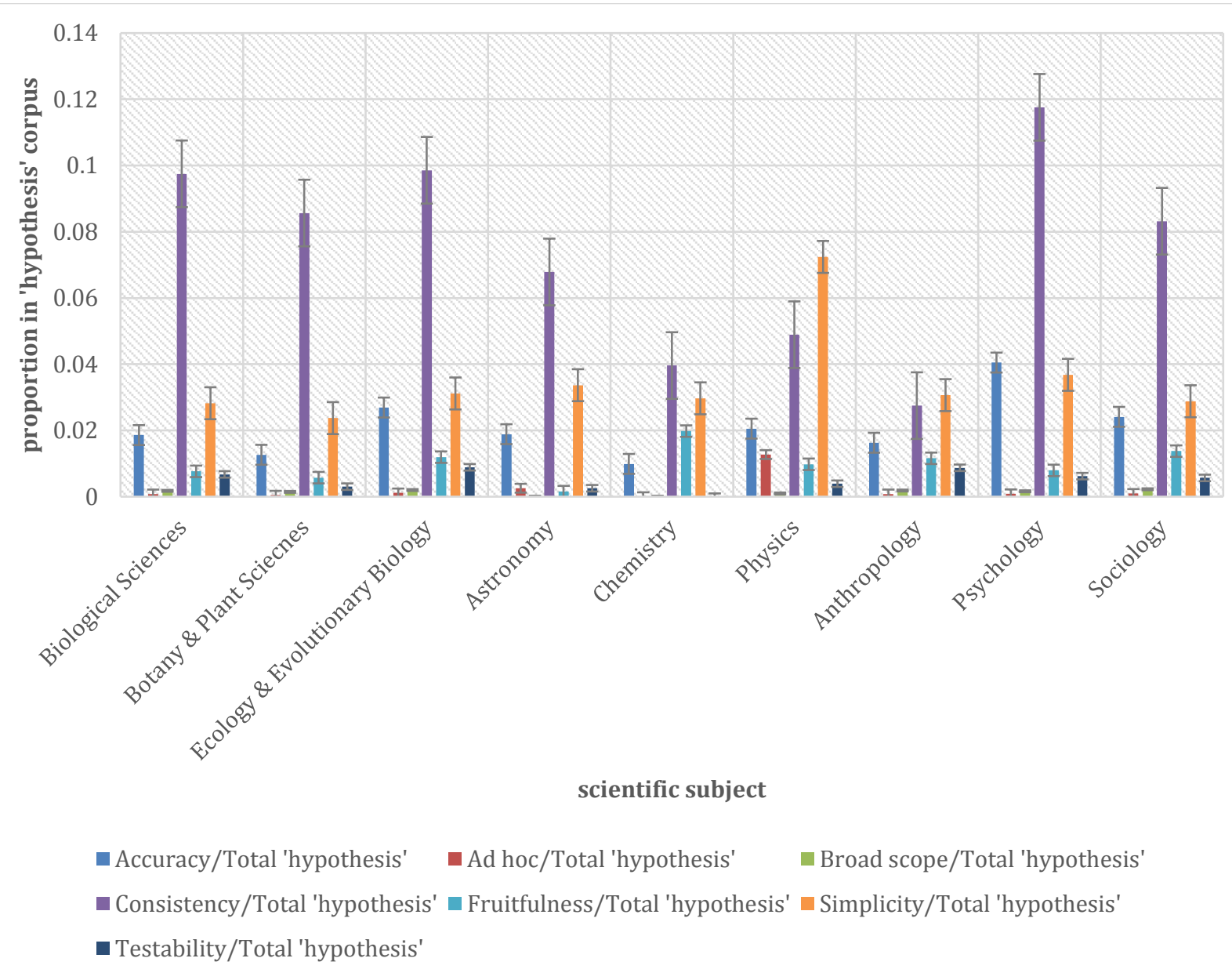

scientific subject

- Accuracy/Total 'hypothesis' —Ad hoc/Total 'hypothesis' \# Broad scope/Total 'hypothesis'

— Consistency/Total 'hypothesis' — Fruitfulness/Total 'hypothesis' $\square$ Simplicity/Total 'hypothesis'

- Testability/Total 'hypothesis'

As far as the physical sciences are concerned, simplicity remains the most frequently invoked theoretical virtue in Physics in the 'hypothesis' corpus as well (7\%). Again, the results of z-tests for proportions suggest that simplicity is invoked significantly more often than the second most frequently invoked theoretical virtue, namely, consistency, in Physics $(\mathrm{z}=2.223, p$ $=0.02$, two-sided). Unlike the 'theory' corpus, the most frequently invoked theoretical virtue in Chemistry and Astronomy is now consistency, not simplicity. However, no statistically significant difference was found between the proportion of consistency in Chemistry publications that contain hypothesis talk (0.03) and the proportion of simplicity in Chemistry publications that contain hypothesis talk $(0.02)(\mathrm{z}=-0.384, p=0.70$, two-sided $)$. On the other hand, the difference between the proportion of consistency in Astronomy publications that contain hypothesis talk (0.06) and the proportion of simplicity in Astronomy publications that contain hypothesis talk (0.03) is statistically significant $(\mathrm{z}=4.874, p=0.00$, two-sided). These results suggest that simplicity is invoked significantly more often than the other theoretical virtues in Physics publications that contain hypothesis talk, whereas consistency is invoked significantly more often than the other theoretical virtues in Astronomy publications that contain hypothesis talk.

As far as Astronomy and Chemistry are concerned, then, there is a noticeable difference between the 'theory' corpus and the 'hypothesis' corpus. In the 'theory' corpus, the most 
frequently mentioned theoretical virtue in both Astronomy and Chemistry is simplicity. In the 'hypothesis' corpus, the most frequently mentioned theoretical virtue in both Astronomy and Chemistry is consistency. The results of z-tests for proportions suggest that these differences between the 'theory' corpus and the 'hypothesis' corpus are statistically significant in Chemistry, but not Astronomy. Specifically, the difference between the proportion of simplicity in Astronomy publications that contain theory talk (0.06) and the proportion of consistency in Astronomy publications that contain hypothesis talk (0.06) is not statistically significant $(\mathrm{z}=-$ $0.480, p=0.63$, two-sided). The difference between the proportion of simplicity in Chemistry publications that contain theory talk (0.1) and the proportion of consistency in Chemistry publications that contain hypothesis talk (0.03) is statistically significant $(\mathrm{z}=-99.844, p=0.00$, two-sided). These results suggest that whether the discussion is about theories or about hypotheses may make a significant difference to the frequency with which simplicity or consistency are invoked in Chemistry publications.

In the life sciences, consistency is the most frequently mentioned theoretical virtue in the context of hypothesis talk: $9 \%$ in the Biological Sciences, $8 \%$ in Botany \& Plant Sciences, and 9\% in Ecology \& Evolutionary Biology. The results of z-tests for proportions suggest that consistency is invoked significantly more often than the second most frequently mentioned theoretical virtue, namely, simplicity, in the Biological Sciences $(\mathrm{z}=102.482, p=0.00$, twosided), Botany \& Plant Sciences ( $\mathrm{z}=47.2275, p=0.00$, two-sided), and Ecology \& Evolutionary Biology $(\mathrm{z}=59.311, p=0.00$, two-sided $)$. These results suggest that simplicity is invoked significantly more often than the other theoretical virtues in Biological Sciences, Botany \& Plant Sciences, and Ecology \& Evolutionary Biology publications that contain hypothesis talk.

In that respect, there is a noticeable difference between the 'theory' corpus and the 'hypothesis' corpus as far as the life sciences are concerned. In the 'hypothesis' corpus, consistency is the most frequently mentioned theoretical virtue in the life sciences. This is different from the 'theory' corpus where simplicity is invoked significantly more often than the other theoretical virtues in Biological Sciences publications, whereas simplicity and consistency are invoked with no significant difference in frequency in Botany \& Plant Sciences and Ecology \& Evolutionary Biology publications. Additional z-tests for proportions were conducted to find that these differences between the 'theory' corpus and the 'hypothesis' corpus as far as the life sciences are concerned are statistically significant. Specifically, the difference between the proportion of simplicity in Biological Sciences publications that contain theory talk $(0.03)$ and the proportion of consistency in Biological Sciences publications that contain hypothesis talk (0.09) is statistically significant $(\mathrm{z}=85.729, p=0.00$, two-sided $)$. Likewise, the difference between the proportion of simplicity in Botany \& Plant Sciences publications that contain theory talk (0.02) and the proportion of consistency in Botany \& Plant Sciences publications that contain hypothesis talk (0.08) is statistically significant $(\mathrm{z}=39.872, p=0.00$, two-sided $)$. Finally, the difference between the proportion of simplicity in Ecology \& Evolutionary Biology publications that contain theory talk (0.03) and the proportion of consistency in Ecology \& Evolutionary Biology publications that contain hypothesis talk (0.09) is statistically significant (z $=59.565, p=0.00$, two-sided). These results suggest that whether the discussion is about theories or about hypotheses may make a significant difference to the frequency with which simplicity or consistency are invoked in Biological Sciences, Botany \& Plant Sciences, and Ecology \& Evolutionary Biology publications. 
In the social sciences, consistency remains the most frequently mentioned theoretical virtue in Psychology (11\%) and Sociology (8\%). Again, Anthropology is the exception among the social sciences insofar as simplicity $(3 \%)$, not consistency $(2 \%)$, is the most frequently mentioned theoretical virtue in the 'hypothesis' corpus as it is in the 'theory' corpus. The result of a z-test for proportions suggests that the difference between the proportion of Anthropology publications that mention simplicity (0.03) and the proportion of Anthropology publications that mention consistency (0.02) in the 'hypothesis' corpus is statistically significant $(\mathrm{z}=2.183, p=$ 0.02 , two-sided). As in the 'theory' corpus, this result suggests that simplicity is invoked significantly more often than the other theoretical virtues in Anthropology publications that contain hypothesis talk. Likewise, the results of z-tests for proportions suggest that consistency is invoked significantly more often than the second most frequently mentioned theoretical virtue, namely, accuracy in Psychology ( $\mathrm{z}=30.758, p=0.00$, two-sided) and simplicity in Sociology ( $\mathrm{z}$ $=43.510, p=0.00$, two-sided). These results suggest that consistency is invoked significantly more often than the other theoretical virtues in Psychology and Sociology publications that contain hypothesis talk.

Overall, theoretical virtues are invoked rather infrequently in the context of hypothesis talk across all the scientific subjects tested in this study. To the extent that theoretical virtues are invoked in scientific practice, however, there are interesting differences between those scientific subjects in the 'hypothesis' corpus as well. In the physical sciences, simplicity plays a more significant role than the other theoretical virtues in Physics publications that contain theory talk or hypothesis talk, but not Astronomy and Chemistry publications. As far as Astronomy and Chemistry publications that contain hypothesis talk are concerned, it is consistency rather than simplicity that plays a more significant role than the other theoretical virtues. In the life sciences, simplicity plays a more significant role than the other theoretical virtues in Biological Sciences, Botany \& Plant Sciences, and Ecology \& Evolutionary Biology publications that contain hypothesis talk, which is unlike those that contain theory talk. In the social sciences, consistency plays a more significant role than the other theoretical virtues in Psychology and Sociology publications that contain hypothesis talk, but not in Anthropology publications where simplicity plays a more significant role than the other theoretical virtues. As in the 'theory' corpus, then, the data from the 'hypothesis' corpus suggest that, when it comes to theoretical virtues, Anthropology is significantly different from the other social sciences.

As discussed in Section 2, in addition to searching for instances of theoretical virtues in the context of theory talk and hypothesis talk, I have also searched for instances of theoretical virtues in the context of model talk. The results of these searches are depicted in Figure 3. As we can see from Figure 3, theoretical virtues occur more frequently in the context of model talk than in the context of theory talk or hypothesis talk, but still rather infrequently overall. Nevertheless, there are interesting differences between the 'model' corpus, the 'hypothesis' corpus, and the 'theory' corpus.

Figure 3. Proportions of publications that contain occurrences of theoretical virtues in the context of model talk by subject (Source: JSTOR Data for Research) 


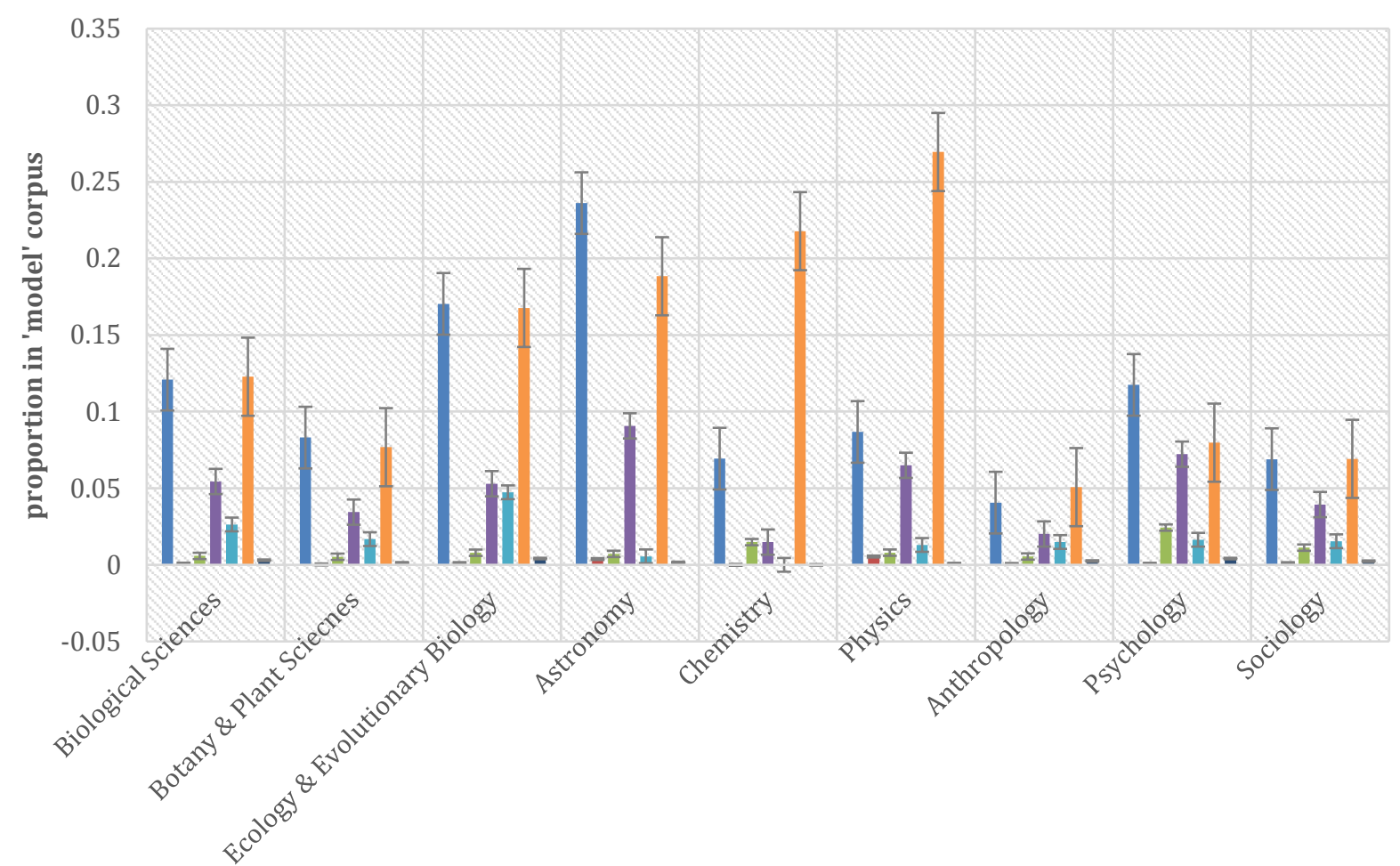

scientific subject

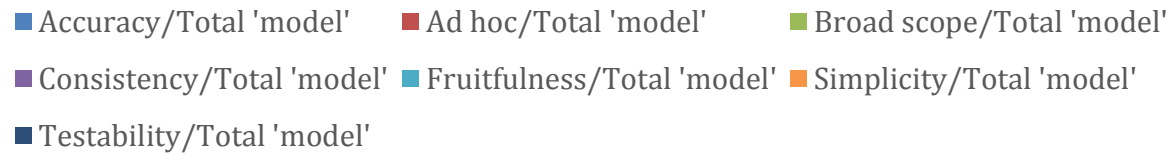

As far as the physical sciences are concerned, simplicity remains the most frequently invoked theoretical virtue in Physics in the 'model' corpus as well (26\%). Also, as in the 'theory' corpus, but not in the 'hypothesis' corpus, simplicity is the most frequently invoked theoretical virtue in Chemistry (21\%). In Astronomy, however, the most frequently invoked theoretical virtue in the context of talk about models is accuracy (23\%). The results of z-tests for proportions suggest that simplicity is invoked significantly more often than the second most frequently invoked theoretical virtue, namely, accuracy, in Physics $(\mathrm{z}=16.495, p=0.00$, twosided) and in Chemistry ( $\mathrm{z}=4.256, p=0.00$, two-sided). In Astronomy, the difference between the proportion of accuracy ( 0.23$)$ and the proportion of simplicity $(0.18)$ in the 'model' corpus is statistically significant $(\mathrm{z}=5.853, p=0.00$, two-sided) as well. These results suggest that simplicity is invoked significantly more often than the other theoretical virtues in Physics and Chemistry publications that contain model talk, whereas accuracy is invoked significantly more often than the other theoretical virtues in Astronomy publications that contain model talk.

As far as Astronomy and Chemistry are concerned, there is a noticeable difference between the 'hypothesis' corpus and the 'model' corpus. In the 'hypothesis' corpus, the most frequently mentioned theoretical virtue in both Astronomy and Chemistry is consistency. In the 'model' corpus, the most frequently mentioned theoretical virtues are accuracy in Astronomy and simplicity in Chemistry. The results of z-tests for proportions suggest that the differences 
between the 'hypothesis' corpus and the 'model' corpus as far as Astronomy and Chemistry publications are concerned are statistically significant. Specifically, the difference between the proportion of consistency in Astronomy publications that contain hypothesis talk (0.06) and the proportion of accuracy in Astronomy publications that contain model talk (0.23) is statistically significant ( $\mathrm{z}=16.142, p=0.00$, two-sided). This result suggests that whether the discussion is about hypotheses or about models may make a significant difference to the frequency with which consistency or accuracy are invoked in Astronomy publications. Likewise, the difference between the proportion of consistency in Chemistry publications that contain hypothesis talk $(0.03)$ and the proportion of simplicity in Chemistry publications that contain model talk (0.21) is statistically significant $(\mathrm{z}=4.005, p=0.00$, two-sided). This result suggests that whether the discussion is about hypotheses or about models may make a significant difference to the frequency with which consistency or simplicity are invoked in Chemistry publications.

In the life sciences, accuracy is the most frequently mentioned theoretical virtue in the context of model talk: $12 \%$ in the Biological Sciences, $8 \%$ in Botany \& Plant Sciences, and 17\% in Ecology \& Evolutionary Biology. In the Biological Sciences, simplicity is also at $12 \%$ in the 'model' corpus. The result of a z-test for proportions suggest that simplicity is invoked significantly more often than the second most frequently mentioned theoretical virtue, namely, accuracy, in the Biological Sciences ( $\mathrm{z}=2.574, p=0.01$, two-sided). On the other hand, the result of a z-test for proportions suggest that accuracy is invoked significantly more often than the second most frequently mentioned theoretical virtue, namely, simplicity, in Botany \& Plant Sciences ( $\mathrm{z}=4.714, p=0.00$, two-sided), but not in Ecology \& Evolutionary Biology ( $\mathrm{z}=1.851$, $p=0.06$, two-sided). These results suggest that simplicity is invoked significantly more often than the other theoretical virtues in Biological Sciences publications that contain model talk, whereas accuracy is invoked significantly more often than the other theoretical virtues in Botany $\&$ Plant Sciences publications that contain model talk.

In that respect, there is a noticeable difference between the 'hypothesis' corpus and the 'model' corpus as far as the life sciences are concerned. In the 'hypothesis' corpus, consistency is the most frequently mentioned theoretical virtue in the life sciences. This is different from the 'model' corpus where simplicity is the most frequently invoked theoretical virtue in the Biological Sciences, whereas accuracy is the most frequently invoked theoretical virtue in Botany \& Plant Sciences. Additional z-tests for proportions were conducted to find that some of these differences between the 'hypothesis' corpus and the 'model' corpus as far as the life sciences are concerned are statistically significant. Specifically, the difference between the proportion of consistency in Biological Sciences publications that contain hypothesis talk (0.09) and the proportion of simplicity in Biological Sciences publications that contain model talk (0.12) is statistically significant ( $\mathrm{z}=-31.447, p=0.00$, two-sided). Likewise, the difference between the proportion of consistency in Ecology \& Evolutionary Biology publications that contain hypothesis talk (0.09) and the proportion of accuracy in Ecology \& Evolutionary Biology publications that contain model talk (0.17) is statistically significant $(\mathrm{z}=-48.576, p=0.00$, twosided). However, the difference between the proportion of consistency in Botany \& Plant Sciences publications that contain hypothesis talk (0.08) and the proportion of accuracy in Botany \& Plant Sciences publications that contain model talk (0.08) is not statistically significant ( $\mathrm{z}=1.758, p=0.07$, two-sided $)$. These results suggest that whether the discussion is about hypotheses or about models may not make a significant difference to the frequency with which 
consistency or accuracy are invoked in Botany \& Plant Sciences publications, but it may make a significant difference to the frequency with which consistency or simplicity are invoked in Biological Sciences publications, and the frequency with which consistency or accuracy are invoked in Ecology \& Evolutionary Biology publications.

In the social sciences, too, accuracy and simplicity (not consistency, as in the 'hypothesis' corpus) are the most frequently mentioned theoretical virtues in Psychology (11\%), Sociology (6\%), and Anthropology (5\%), respectively. In Sociology, in addition to simplicity, accuracy is also at $6 \%$ in the 'model' corpus. The result of a z-test for proportions suggests that the difference between the proportion of simplicity in Sociology publications that contain model talk (0.06) and the proportion of accuracy in Sociology publications that contain model talk (0.06) is not statistically significant $(\mathrm{z}=0.230, p=0.81$, two-sided). On the other hand, the result of a z-test for proportions suggests that accuracy is invoked significantly more often than the second most frequently mentioned theoretical virtue, namely, simplicity, in Psychology $(\mathrm{z}=$ $16.456, p=0.00$, two-sided). Likewise, the result of a z-test for proportions suggests that simplicity is invoked significantly more often than the second most frequently mentioned theoretical virtue, namely, accuracy, in Anthropology $(\mathrm{z}=8.732, p=0.00$, two-sided $)$. These results suggest that simplicity is invoked significantly more often than the other theoretical virtues in Anthropology publications that contain model talk, whereas accuracy is invoked significantly more often than the other theoretical virtues in Psychology publications that contain model talk.

In that respect, there is a noticeable difference between the 'hypothesis' corpus and the 'model' corpus as far as the social sciences are concerned. In the 'hypothesis' corpus, consistency is the most frequently mentioned theoretical virtue in Psychology and Sociology, but not in Anthropology. This is different from the 'model' corpus where accuracy is the most frequently invoked theoretical virtue in Psychology and Sociology, whereas simplicity is the most frequently invoked theoretical virtue in Anthropology. Additional z-tests for proportions were conducted to find out whether these differences between the 'hypothesis' corpus and the 'model' corpus as far as Psychology and Sociology are concerned are statistically significant. The difference between the proportion of consistency in Psychology publications that contain hypothesis talk (0.11) and the proportion of accuracy in Psychology publications that contain model talk (0.11) is not statistically significant $(\mathrm{z}=-0.036, p=0.97$, two-sided). On the other hand, the difference between the proportion of consistency in Sociology publications that contain hypothesis talk (0.08) and the proportion of accuracy in Sociology publications that contain model talk (0.06) is statistically significant $(\mathrm{z}=12.036, p=0.00$, two-sided). These results suggest that whether the discussion is about hypotheses or about models may not make a significant difference to the frequency with which consistency or accuracy are invoked in Psychology publications, but it may make a significant difference to the frequency with which consistency or accuracy are invoked in Sociology publications.

Overall, theoretical virtues occur more frequently in the context of model talk than in the context of theory talk or hypothesis talk, but still somewhat infrequently overall. To the extent that theoretical virtues are invoked in scientific practice, however, there are interesting differences between those scientific subjects in the 'model' corpus as well. In the physical sciences, simplicity plays a more significant role than the other theoretical virtues in Physics and 
Chemistry publications that contain model talk, but not Astronomy publications. As far as Astronomy publications that contain model talk are concerned, it is accuracy rather than consistency (as in the 'hypothesis' corpus) or simplicity (as in the 'theory' corpus) that plays a more significant role than the other theoretical virtues. In the life sciences, accuracy and simplicity play a more significant role than the other theoretical virtues in Biological Sciences, Botany \& Plant Sciences, and Ecology \& Evolutionary Biology publications that contain model talk, which is unlike those that contain hypothesis talk. In the social sciences, too, accuracy and simplicity play a more significant role than the other theoretical virtues in Anthropology, Psychology, and Sociology publications that contain hypothesis talk, which is unlike those that contain hypothesis talk, with the exception of Anthropology publications. Interestingly, in the data mined from the 'model' corpus, Anthropology exhibits patterns similar to the other social sciences, which is different from the patterns found in the 'theory' corpus and the 'hypothesis' corpus.

\section{Discussion}

As discussed in Section 1, this empirical study was designed to address the following questions about the role of theoretical virtues in scientific practice: Do scientists make explicit appeals to theoretical virtues in scientific practice? If so, which theoretical virtues? How frequently do scientists appeal to those theoretical virtues? Do they invoke some theoretical virtues more than others? If so, which ones?

The results of this study allow us to formulate tentative answers to these questions. The results suggest that scientists do make explicit appeals to theoretical virtues in scientific practice. That is, this study was designed to test the view, which is widely accepted among philosophers of science, that theoretical virtues play an important role in scientific practice. Now, if theoretical virtues play an important role in scientific practice, such that they 'guide [scientists] in their choice to adopt one theory or another' (Schindler [2018a], p. 5), then we would expect to see frequent occurrences of the search terms for theoretical virtues paired with the scientific practice terms (namely, 'hypothesis', 'model', and 'theory'). As expected if theoretical virtues play an important role in scientific practice, we do see occurrences of our search queries in scientific publications. This finding suggests that scientists do make explicit appeals to theoretical virtues in scientific practice.

The results also suggest that scientists invoke some theoretical virtues more than others, depending on the scientific subject and the context in which the terms for theoretical virtues occur. Across all the scientific subjects tested in this study, simplicity and consistency are invoked more frequently than the other theoretical virtues in the context of theory talk and hypothesis talk, whereas accuracy and simplicity are invoked more frequently than the other theoretical virtues in the context of model talk. This finding suggests that there may be a significant difference between hypotheses and theories, on the one hand, and models, on the other hand, such that accuracy is more important when it comes to models, whereas consistency is more important when it comes to hypotheses and theories (although simplicity is important in hypotheses, theories, and models). Another possibility is that theoretical virtues are a trade-off. That is, as far as models are concerned, if scientists are 'unable to construct models that simultaneously exemplify every theoretical virtue', as Matthewson and Weisberg ([2009], p. 
169) argue, then they may have to trade off some theoretical virtues for others. This, in turn, might explain why there are more explicit mentions of some theoretical virtues than others in scientific publications that contain model talk.

For philosophers of science, this finding suggests that perhaps hypotheses, models, and theories should be kept apart more clearly in philosophical discussions that feature them. In philosophical discussions of confirmation, for instance, the terms 'hypothesis' and 'theory' are often used interchangeably (see, for example, Douglas and Magnus [2013]). If there is a significant difference between theories and hypotheses in scientific practice, such that the former need to be simple, whereas the latter need to be consistent, as the results of this study suggest, then perhaps philosophers of science should distinguish between theories and hypotheses more carefully.

Even though the results of this study show that there are explicit appeals to theoretical virtues in scientific publications, the proportions may not be as high as one might expect if theoretical virtues really did play an important role in theory choice. That is, if theoretical virtues really do play an important role in scientific practice, one might expect to see them invoked in scientific publications more frequently than the results suggest. For they suggest that theoretical virtues do not occur all that frequently in scientific practice. In the context of hypothesis talk, they occur in less than $15 \%$ of scientific publications across the life, physical, and social sciences. In the context of theory talk, they occur in less than $20 \%$ of scientific publications across the life, physical, and social sciences. And in the context of model talk, they occur in less than $30 \%$ of scientific publications across the life, physical, and social sciences.

Moreover, given the importance that philosophers of science typically assign to specific theoretical virtues, it is surprising to find that those theoretical virtues are rarely mentioned in scientific publications across the life, physical, and the social sciences. For example, although the data show that there are explicit appeals to fruitfulness, it is rarely invoked in scientific publications across the life, physical, and social sciences. This is a surprising finding, especially considering the importance that philosophers of science typically assign to fruitfulness. For instance, according to Longino ([1996], p. 44):

[Kuhn] is correct in identifying [fruitfulness] as a criterion used by scientists in evaluating theories. A fruitful theory generates new findings or discloses new relationships.

However, the results suggest that fruitfulness is rarely invoked in scientific practice (less than $0.01 \%$ in the context of hypothesis talk, less than $0.02 \%$ in the context of theory talk, and less than $0.04 \%$ in the context of model talk across the life, physical, and social sciences).

Likewise, although the data show that there are explicit appeals to accuracy, it is rarely invoked in scientific publications that contain theory talk across the life, physical, and social sciences. This is also a surprising finding, especially considering the importance that philosophers of science, especially antirealists, typically assign to accuracy. For instance, following van Fraassen ([1980], p. 40), Monton and Mohler ([2017]) claim that the 'scientific competition between theories hinges on which theory accurately describes the observable world; 
it does not hinge on which theory is actually true'. If, as constructive empiricists claim, 'Science aims to give us theories which are empirically adequate' (van Fraassen [1980], p. 12), that is, theories that accurately describe the observable world, then one would expect frequent appeals to accuracy in scientific publications. As we have seen, however, accuracy is appealed to somewhat infrequently in scientific publications that contain theory talk (less than 7\%). Such findings, I submit, should lead philosophers of science to rethink the role that specific theoretical virtues, such as fruitfulness and accuracy, supposedly play in scientific practice.

Even if the proportions of theoretical virtues in scientific corpora may not be as high as one might expect if theoretical virtues really did play an important role in theory choice, the results of this study should not be construed as a refutation of the view that theoretical virtues play an important role in scientific practice. For, like the results of any empirical study, the results of this study are by no means definitive. As discussed in Section 2, it is possible that scientists value theoretical virtues, which guide them in theory choice, but that scientists simply do not invoke theoretical virtues explicitly in their published work all that frequently. It could also be the case that scientific publications that are concerned with theory construction would contain more appeals to theoretical virtues than scientific publications that are concerned with empirical testing. With a method of distinguishing between theoretical and empirical publications in science, we may be able to get a better sense of how frequently theoretical virtues are invoked in theoretical publications. In that respect, more empirical studies are needed in order to understand the role that theoretical virtues play in scientific practice, especially the differences between scientific fields with respect to the theoretical virtues that practitioners in these fields may value in their hypotheses, models, and theories. 


\section{Appendix}

A complete list of theoretical virtue cum scientific practice search queries:

\begin{tabular}{|c|c|c|c|}
\hline & Hypothesis & Model & Theory \\
\hline Accuracy & $\begin{array}{l}\text { ("accuracy } \\
\text { hypothesis" } 10 \text { ) OR } \\
\text { ("accurate } \\
\text { hypothesis" 10) OR } \\
\text { ("accurately } \\
\text { hypothesis" } 10 \text { ) OR } \\
\text { ("fit hypothesis" } 10 \text { ) } \\
\text { OR ("fitting } \\
\text { hypothesis" } ~ 10 \text { ) OR } \\
\text { ("match hypothesis" 10) } \\
\text { OR ("matching } \\
\text { hypothesis" 10) }\end{array}$ & 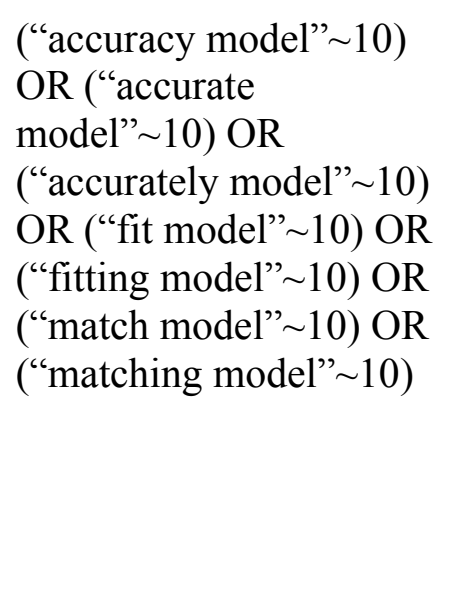 & $\begin{array}{l}\text { ("accuracy theory" } 10 \text { ) } \\
\text { OR ("accurate } \\
\text { theory" } 10 \text { ) OR } \\
\text { ("accurately theory" } 10 \text { ) } \\
\text { OR ("fit theory" 10) OR } \\
\text { ("fitting theory" } 10 \text { ) OR } \\
\text { ("match theory" } ~ 10 \text { ) OR } \\
\text { ("matching theory" 10) }\end{array}$ \\
\hline Ad hocness & $\begin{array}{l}\text { ("ad hoc } \\
\text { hypothesis" } 10 \text { ) OR } \\
\text { ("ad hocness } \\
\text { hypothesis" } 10 \text { ) }\end{array}$ & $\begin{array}{l}\text { ("ad hoc model" } 10) \text { OR } \\
\text { ("ad hocness } \\
\text { model" 10) }\end{array}$ & $\begin{array}{l}\text { ("ad hoc theory" } 10 \text { ) } \\
\text { OR ("ad hocness } \\
\text { theory" 10) }\end{array}$ \\
\hline $\begin{array}{l}\text { Breadth of } \\
\text { scope }\end{array}$ & $\begin{array}{l}\text { ("breadth scope } \\
\text { hypothesis" 10) OR } \\
\text { ("broad scope } \\
\text { hypothesis" 10) OR } \\
\text { ("comprehensive } \\
\text { hypothesis" 10) OR } \\
\text { ("comprehensively } \\
\text { hypothesis" 10) OR } \\
\text { ("comprehensiveness } \\
\text { hypothesis" } 10 \text { ) }\end{array}$ & $\begin{array}{l}\text { ("breadth scope } \\
\text { model" } 10 \text { ) OR ("broad } \\
\text { scope model" } 10 \text { ) OR } \\
\text { ("comprehensive } \\
\text { model" } 10 \text { ) OR } \\
\text { ("comprehensively } \\
\text { model" } 10 \text { ) OR } \\
\text { ("comprehensiveness } \\
\text { model" } 10 \text { ) }\end{array}$ & $\begin{array}{l}\text { ("breadth scope } \\
\text { theory" } 10 \text { ) OR ("broad } \\
\text { scope theory" } 10 \text { ) OR } \\
\text { ("comprehensive } \\
\text { theory" } 10 \text { ) OR } \\
\text { ("comprehensively } \\
\text { theory" } 10 \text { ) OR } \\
\text { ("comprehensiveness } \\
\text { theory" } 10 \text { ) }\end{array}$ \\
\hline Consistency & $\begin{array}{l}\text { ("coherence } \\
\text { hypothesis" 10) OR } \\
\text { ("coherent } \\
\text { hypothesis" 10) OR } \\
\text { ("coherently } \\
\text { hypothesis" 10) OR } \\
\text { ("consistency } \\
\text { hypothesis" 10) OR } \\
\text { ("consistent } \\
\text { hypothesis" 10) OR } \\
\text { ("consistently }\end{array}$ & $\begin{array}{l}\text { (“coherence model" } 10) \\
\text { OR ("coherent } \\
\text { model" } 10 \text { ) OR } \\
\text { ("coherently model" } 10) \\
\text { OR ("consistency } \\
\text { model" } 10 \text { ) OR } \\
\text { (“consistent model" } 10) \\
\text { OR ("consistently } \\
\text { model" } 10)\end{array}$ & $\begin{array}{l}\text { ("coherence theory" } 10 \text { ) } \\
\text { OR ("coherent } \\
\text { theory" } 10 \text { ) OR } \\
\text { ("coherently theory" } 10 \text { ) } \\
\text { OR ("consistency } \\
\text { theory" } 10 \text { ) OR } \\
\text { ("consistent theory" } 10 \text { ) } \\
\text { OR ("consistently } \\
\text { theory" } 10 \text { ) }\end{array}$ \\
\hline
\end{tabular}




\begin{tabular}{|c|c|c|c|}
\hline & hypothesis" 10) & & \\
\hline Fruitfulness & $\begin{array}{l}\text { ("fecund } \\
\text { hypothesis" 10) OR } \\
\text { ("fecundity } \\
\text { hypothesis" 10) OR } \\
\text { ("fertile hypothesis" 10) } \\
\text { OR ("fertility } \\
\text { hypothesis" 10) OR } \\
\text { ("fruitful } \\
\text { hypothesis" } 10 \text { ) OR } \\
\text { ("fruitfully } \\
\text { hypothesis" 10) OR } \\
\text { ("fruitfulness } \\
\text { hypothesis" 10) OR } \\
\text { ("predictive } \\
\text { hypothesis" } 10 \text { ) OR } \\
\text { ("predictively } \\
\text { hypothesis" 10) }\end{array}$ & 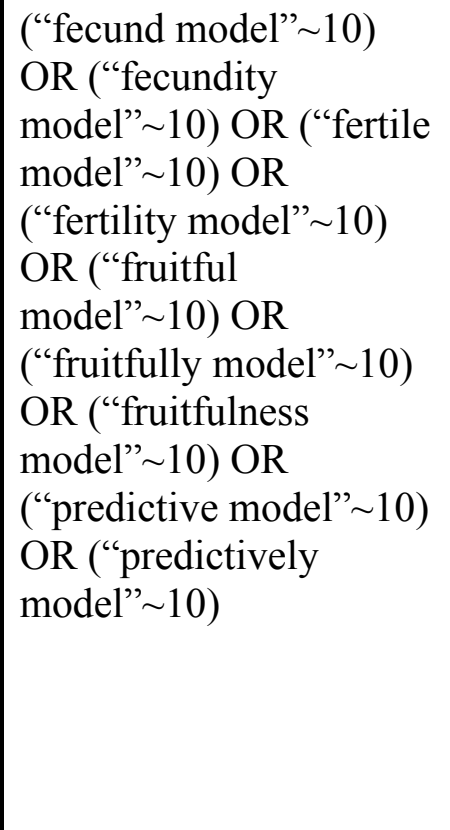 & $\begin{array}{l}\text { ("fecund theory" } 10 \text { ) } \\
\text { OR ("fecundity } \\
\text { theory" } 10 \text { ) OR ("fertile } \\
\text { theory" } 10 \text { ) OR } \\
\text { ("fertility theory" } 10 \text { ) } \\
\text { OR ("fruitful } \\
\text { theory" } \sim 10 \text { ) OR } \\
\text { ("fruitfully theory" } \sim 10 \text { ) } \\
\text { OR ("fruitfulness } \\
\text { theory" } \sim 10 \text { ) OR } \\
\text { ("predictive theory" } 10 \text { ) } \\
\text { OR ("predictively } \\
\text { theory" } \sim 10 \text { ) }\end{array}$ \\
\hline Simplicity & $\begin{array}{l}\text { ("elegance } \\
\text { hypothesis" 10) OR } \\
\text { ("elegant } \\
\text { hypothesis" 10) OR } \\
\text { ("elegantly } \\
\text { hypothesis" 10) OR } \\
\text { ("parsimonious } \\
\text { hypothesis" 10) OR } \\
\text { ("parsimoniously } \\
\text { hypothesis" 10) OR } \\
\text { ("parsimony } \\
\text { hypothesis" 10) OR } \\
\text { ("simple } \\
\text { hypothesis" 10) OR } \\
\text { ("simplicity } \\
\text { hypothesis" 10) OR } \\
\text { ("simplified } \\
\text { hypothesis" 10) OR } \\
\text { ("simpler } \\
\text { hypothesis" 10) OR } \\
\text { ("simplest } \\
\text { hypothesis" 10) OR } \\
\text { ("simply } \\
\text { hypothesis" 10) }\end{array}$ & 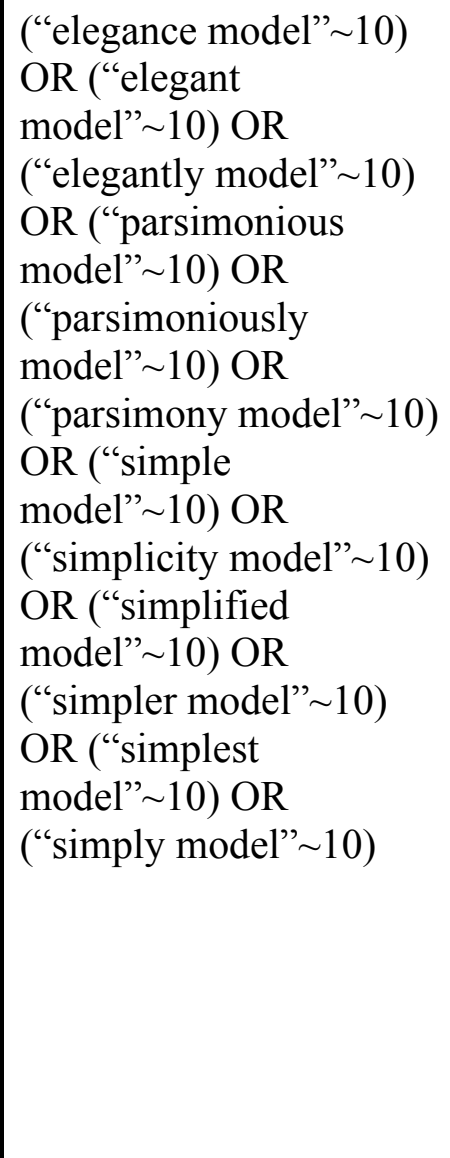 & 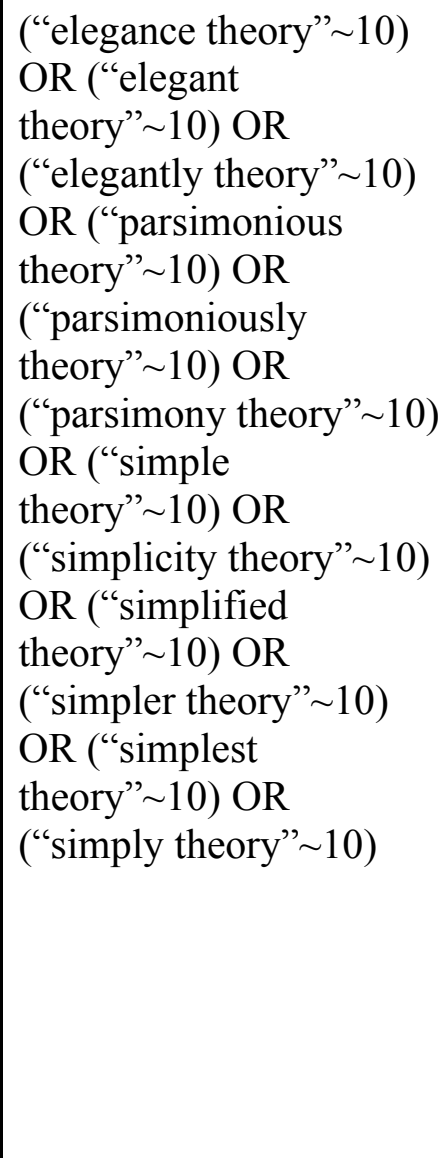 \\
\hline
\end{tabular}




\begin{tabular}{|c|c|c|c|}
\hline Testability & $\begin{array}{l}\text { ("testable } \\
\text { hypothesis" 10) OR } \\
\text { ("testability } \\
\text { hypothesis" 10) }\end{array}$ & $\begin{array}{l}\text { ("testable model" } 10) \\
\text { OR ("testability } \\
\text { model" } 10)\end{array}$ & $\begin{array}{l}\text { ("testable theory" } 10) \\
\text { OR ("testability } \\
\text { theory" } 10)\end{array}$ \\
\hline
\end{tabular}

\title{
Acknowledgements
}

I am very grateful to two anonymous referees of The British Journal for Philosophy of Science for their invaluable comments on earlier drafts of this paper.

\author{
Moti Mizrahi \\ Florida Institute of Technology \\ Melbourne, FL USA \\ mmizrahi@fit.edu
}

\section{References}

Attrill, M.J. [2002]: 'A Testable Linear Model for Diversity Trends in Estuaries', Journal of Animal Ecology, 71, pp. 262-269.

Baker, A. [2016]: 'Simplicity', in E. N. Zalta (ed.), Stanford Encyclopedia of Philosophy, available at <https://plato.stanford.edu/archives/win2016/entries/simplicity/>.

Beebe, J.R. and Dellsén, F. [2020]: 'Scientific Realism in the Wild: An Empirical Study of Seven Sciences and HPS', Philosophy of Science, 87, pp. 336-364.

Bolinska, A., and Martin, J.D. [2019]: 'Negotiating History: Contingency, Canonicity, and Case Studies', Studies in History and Philosophy of Science, available at <https://doi.org/10.1016/j.shpsa.2019.05.003>.

Boss, W.F. and Mott, R.L. [1980]: 'Effects of Divalent Cations and Polyethylene Glycol on the Membrane Fluidity of Protoplast', Plant Physiology, 66, pp. 835-837.

Díaz-Muñoz, S.L., Boddy, A.M., Dantas, G., Waters, C.M., and Bronstein, J.L. [2016]: 'Contextual Organismality: Beyond Pattern to Process in the Emergence of Organisms', Evolution, 70, pp. 2669-2677.

Douglas, H. and Magnus, P.D. [2013]: 'State of the Field: Why Novel Prediction Matters', Studies in History and Philosophy of Science, 44, pp. 580-589.

Duriscoe, D.M. [2013]: 'Measuring Anthropogenic Sky Glow Using a Natural Sky Brightness Model', Publications of the Astronomical Society of the Pacific, 125, pp. 1370-1382.

Elgin, C.Z. [2017]: True Enough, Cambridge: MIT Press. 
Frank, S.A. and Vogelstein, B. [2005]: 'Age-Specific Incidence of Inherited versus Sporadic Cancers: A Test of the Multistage Theory of Carcinogenesis', Proceedings of the National Academy of Sciences of the United States of America, 102, pp. 1071-1075.

Herrera, C.M. [2011]: 'Complex Implications around a Simple Trait: Ecological Context Determines the Fecundity Effects of Corolla Marcescence', American Journal of Botany, 98, pp. 812-818.

Ivani, S. [2019]: 'What We (Should) Talk about When We Talk about Fruitfulness', European Journal for Philosophy of Science, 9, pp. 1-18.

Keas, M.N. [2018]: 'Systematizing the Theoretical Virtues', Synthese, 195, pp. 2761-2793.

Kuhn, T.S. [2000]: 'Afterwords', in J. Conant and J. Haugeland (eds.), The Road Since Structure, Chicago: University of Chicago Press, pp. 224-252.

Laudan, L. [1984]: Science and Values: The Aims of Science and Their Role in Scientific Debate, Berkeley: University of California Press.

Longino, H.E. [1995]: 'Gender, Politics, and the Theoretical Virtues', Synthese, 104, pp. 383397.

Longino, H.E. [1996]: 'Cognitive and Non-Cognitive Values in Science: Rethinking the Dichotomy', in L.H. Nelson and J. Nelson (eds.), Feminism, Science, and the Philosophy of Science, Dordrecht: Kluwer Academic Publishers, pp. 39-58.

Machery, E. [2016]: 'Experimental Philosophy of Science', in J. Sytsma and W. Buckwalter (eds.), A Companion to Experimental Philosophy, Malden, MA: Wiley Blackwell, pp. 475-490.

Matthewson, J. and Weisberg, M. [2009]: 'The Structure of Tradeoffs in Model Building', Synthese, 170, pp. 169-170.

Mizrahi, M. [2013]: 'The Pessimistic Induction: A Bad Argument Gone Too Far', Synthese, 190, pp. 3209-3226.

Mizrahi, M. [2016]: 'The History of Science as a Graveyard of Theories: A Philosophers' Myth?' International Studies in the Philosophy of Science, 30, pp. 263-278.

Mizrahi, M. [2020]: 'The Case Study Method in Philosophy of Science: An Empirical Study', Perspectives on Science, 28, pp. 63-88.

Monton, B. and Mohler, C. [2017]: 'Constructive Empiricism', in E.N. Zalta (ed.), Stanford Encyclopedia of Philosophy, available at $<$ https://plato.stanford.edu/archives/sum2017/entries/constructive-empiricism/>. 
Nolan, D. [1999]: 'Is Fertility Virtuous in Its Own Right?' British Journal for the Philosophy of Science, 50, pp. 265-282.

O’Dea, C.P. [1998]: 'The Compact Steep-Spectrum and Gigahertz Peaked-Spectrum Radio Sources', Publications of the Astronomical Society of the Pacific, 110, pp. 493-532.

Pitt, J.C. [2001]: 'The Dilemma of Case Studies: Toward a Heraclitian Philosophy of Science', Perspectives on Science, 9, pp. 373-382.

Sauer, T. and Scholl, R. [2016]: 'Introduction', in T. Sauer and R. Scholl (eds.), The Philosophy of Historical Case Studies, Basel: Springer, pp. 1-10.

Schindler, S. [2018a]: Theoretical Virtues in Science: Uncovering Reality through Theory, Cambridge: Cambridge University Press.

Schindler, S. [2018b]: 'A Coherentist Conception of Ad Hoc Hypotheses', Studies in History and Philosophy of Science, 67, pp. 54-64.

Schindler, S. and Saint-Germier, P. [2019]: 'Are Thought Experiments "Disturbing"? The Case of Armchair Physics', Philosophical Studies, available at <https://doi.org/10.1007/s11098-01901333-w>.

Tomasello, M., Melis, A.P., Tennie, C., Wyman, E., and Herrmann E. [2012]: 'Two Key Steps in the Evolution of Human Cooperation: The Interdependence Hypothesis', Current Anthropology, 53, pp. 673-692.

Van Fraassen, B.C. [1980]: The Scientific Image, Oxford: Clarendon Press.

Young, T. [1805]: 'An Essay on the Cohesion of Fluids', Philosophical Transactions of the Royal Society of London, 95, pp. 65-87. 